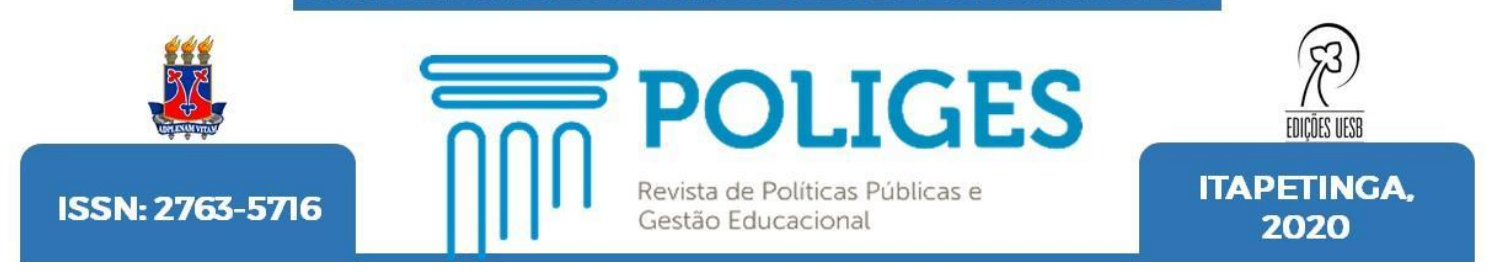

\title{
AGROECOLOGIA E EMPODERAMENTO DE MULHERES DE UMA COMUNIDADE SERTANEJA DO SEMIÁRIDO BAIANO
}

\author{
AGROECOLOGY AND EMPOWERMENT OF WOMEN FROM A COMMUNITY IN \\ BAHIA'S SEMIARID REGION
}

\begin{abstract}
AGROECOLOGÍA Y EMPODERAMIENTO DE MUJERES DE UNA COMUNIDAD SERTANEJA EN LA SEMIÁRIDA BAHIANA
\end{abstract}

Carina de Moraes Pereira Brito

ORCID iD: https://orcid.org/0000-0002-2424-6473

Universidade Federal do Recôncavo da Bahia - UFRB - Brasil

Priscila Brasileiro Silva do Nascimento

ORCID iD: https://orcid.org/0000-0001-7742-2023

Universidade Federal do Recôncavo da Bahia - UFRB - Brasil

\begin{abstract}
Resumo: O presente artigo busca refletir como as experiências agroecológicas desenvolvidas dentro de um grupo produtivo solidário vem contribuindo para o avanço na busca pelo empoderamento feminino em uma comunidade sertaneja do semiárido baiano. O embasamento desta pesquisa deu-se partir da análise dos seguintes elementos problematizadores: a Agroecologia como modelo de produção contra hegemônico ao agronegócio, que vem refletindo as consequências do modelo de produção capitalista; a possibilidade de pensar a Agroecologia como um modelo de agricultura alternativa que se faz necessária para a modificação do setor de produção de alimentos no mundo; o desenvolvimento de experiências de transição agroecológica no semiárido baiano, onde é apresentado as adversidades enfrentadas na região relacionada aos meios de sobrevivência e ao mesmo tempo, as diversas alternativas existentes para que se possa ter qualidade de vida, principalmente por meio das práticas de extrativismo e trabalho comunitário; a contribuição das práticas agroecológicas no processo de construção do empoderamento de mulheres camponesas e por fim, a Agroecologia como empoderamento feminino, usando como estudo de caso as mulheres sertanejas da comunidade Salgado e suas experiências no grupo produtivo "Mulheres de Esperança". Para tanto, a metodologia utilizada foi a qualitativa, sendo o estudo de caso a opção demandada pela natureza da investigação. Através da pesquisa, foi possível perceber que a Agroecologia constitui uma importante via de transformação pois engendra mudanças profundas na organização produtiva formada pela força de mulheres que buscam a transformação do modo de vida no que tange o aspecto social, cultural, político, financeiro e organizacional de sua localidade.
\end{abstract}

Palavras-chave: Agroecologia; Grupos Produtivos; Mulheres camponesas 


\begin{abstract}
The present paper seeks to reflect how the agroecological experiences developed within a solidary productive group, and how it has contributed to the advancement in the,search for female empowerment in a "sertaneja" (people leaving in backlands, like outback lands in Australia) community in the semi-arid region of Bahia. The basis of this research was based upon the analysis of following questioning elements: agroecology as a production model against the hegemonic agribusiness model, and how it has reflected the consequences of the capitalist production system; the possibility of thinking about agroecology as an alternative agriculture model that is necessary for the modification of this production sector in the world; the development of agroecological transition experiences in the semi-arid region of Bahia, where the adversities faced in the region related to the means of subsistence are presented and, at the same time, several alternatives in order to put forward their quality of life, mainly through extractive practices and community work; the contribution of agroecological practices in the process of empowerment of peasant women; finally, agroecology as a female empowerment, through the "sertanejas" woman from the Salgado community as a case study and their experiences in the productive group "Mulheres de Esperança". For that, the methodology was qualitative, a case study, the option demanded by the goals of our inquire. Through this research was possible to realize that Agroecology is an important pathway to transformation because it engenders profound changes in the productive organization formed by women workforce who seek the transformation of their way of life regarding social, cultural, political, financial, and organizational means.
\end{abstract}

Keywords: Agroecology; Productive Groups; Peasant women

Resumen: Este artículo busca reflejar cómo las experiencias agroecológicas desarrolladas dentro de un grupo productivo solidario han contribuido al avance en la búsqueda del empoderamiento femenino en una comunidad del interior de la región semiárida de Bahía. La base de esta investigación se basó en el análisis de los siguientes elementos problematizadores: la agroecología como modelo productivo frente a la hegemonía frente al agronegocio, que viene reflejando las consecuencias del modelo productivo capitalista; la posibilidad de pensar en la agroecología como un modelo de agricultura alternativo que es necesario para la modificación del sector de producción de alimentos en el mundo; el desarrollo de experiencias de transición agroecológica en la región semiárida de Bahía, donde se presenten las adversidades que enfrenta la región relacionadas con los medios de supervivencia y, al mismo tiempo, las diversas alternativas que existen para tener calidad de vida, principalmente a través de prácticas extractivas y trabajo comunitario; el aporte de las prácticas agroecológicas en el proceso de construcción del empoderamiento de la mujer campesina y, finalmente, la agroecología como empoderamiento femenino, tomando como caso de estudio a las mujeres del campo de la comunidad de Salgado y sus experiencias en el grupo productivo "Mulheres de Esperança". Para ello, la metodología utilizada fue cualitativa, siendo el estudio de caso la opción exigida por la naturaleza de la investigación. A través de la investigación se pudo concretar que la Agroecología es una vía de transformación importante porque engendra profundos cambios en la organización productiva formada por la fuerza de las mujeres que buscan la transformación de la forma de vida en lo social, cultural, político, social. aspectos financieros y organizativos de su localidad.

Palabras clave: Agroecología; Grupos productivos; Mujeres campesinas

Revista de Políticas Públicas e Gestão Educacional (POLIGES) - UESB-Itapetinga. ISSN: 2763-5716Ano 2020, Volume 1, número 1, set. - dez. de 2020. 


\section{Introdução}

Existem diferentes orientações na tentativa de determinar o que seria a verdadeira prática da Agroecologia: muitos a apresentam de forma equivocada ou pouco correspondem ao que define essa ciência, já outras se baseiam em uma visão limitada, apresentando a Agroecologia como mera técnica agrícola que visa à sustentabilidade ou a sobreposição de procedimentos da agricultura convencional.

No entanto, a Agroecologia está para além desses conceitos básicos, ultrapassando a simples lógica de produção, caracterizando-se não só pelas práticas de uma agricultura sustentável, mas, também intercalando um conjunto de princípios ecológicos e ideias de transformações em todo processo dinâmico de produção e reestruturação da sociedade, o que a torna para além de uma técnica agrícola, um posicionamento político a partir das experiências cultivadas na relação entre homem/mulher/ natureza e projeto de desenvolvimento de país.

Assim, este trabalho visa analisar os espaços de transição agroecológica e a relação com as mulheres, bem como os espaços de destaque e interação o qual estas estão inseridas, tendo aqui como referência o grupo de produção Mulheres de Esperança da comunidade de Salgado, que hoje tem aproximadamente 200 famílias que vivem principalmente da produção e comercialização de produtos oriundos da agricultura, como hortaliças, frutas e verduras e pecuária, com a criação de caprinos, ovinos, aves e suínos, todos baseados no processo de transição agroecológica. Além disso, o grupo conta com algumas instituições que contribuem e fortalecem a organização e geração de renda da localidade.

A comunidade está situada no município de Monte Santo-BA, localizado no Território de Identidade do Sisal, na região semiárida do Nordeste. De acordo com o censo de 2010 do IBGE o município tem aproximadamente 52.338 habitantes, com o maior número de pessoas na zona rural, cerca de $83 \%$. Sua base econômica é oriunda principalmente da agropecuária, com criação de animais de pequeno e médio porte e o plantio de feijão, milho e mandioca. O município vem se desenvolvendo e fortalecendo através das comunidades com base na agricultura familiar, com a produção e comercialização de produtos agrícolas e pecuários.

Diante do exposto, a presente pesquisa parte do lugar de experiência onde o 
grupo está situado e buscou compreender diretamente os aspectos que podem gerar o avanço da autonomia das mulheres camponesas e contribuir na transformação das relações de gênero, na perspectiva da superação da cultura patriarcal na comunidade, uma vez que, em consequência desta estrutura enraizada em todo o mundo, a mulher geralmente é tida como inferior aos homens, tanto nos quesitos de força física, quanto em sua capacidade de atuação na política, nas atividades produtivas, nos espaços de debates e como liderança. Nesta perspectiva, sua única função seria a de reproduzir, cuidar dos filhos e do lar e ser dependente e submissa ao marido.

À medida que mulheres começam a romper com os tabus que permeiam sua construção social é levantado o debate sobre o modelo produtivo adotado e suas implicações para o desenvolvimento econômico, o que coloca em discussão a dependência financeira e o empoderamento que estas podem passar a desenvolver em função da autonomia criada.

O alicerce desta pesquisa baseia-se na reflexão da organização produtiva do Grupo Mulheres de Esperança, bem como das transformações promovidas na vida social das envolvidas a partir das experiências do grupo de produção compreendendo seu potencial de transição agroecológica.

Quanto à metodologia da realização deste trabalho, constata-se que esta é uma pesquisa de caráter social, pois levantou-se dados sobre a participação da mulher no trabalho conjunto para a produção de alimentos. As colaboradoras da pesquisa foram doze mulheres camponesas, que integram grupos de produção e beneficiamento de alimentos da cultura local do município de Monte Santo. São mães de família, que vivem da produção da roça, mas ainda assim acabam tendo grandes dificuldades de autonomia financeira. Estas possuem faixa etária entre 35 a 50 anos. 
Quanto à perspectiva metodológica, optamos pela pesquisa qualitativa, sendo definida por Machado (2017) como uma série de métodos e técnicas que podem ser usadas para uma análise mais aprofundada das relações sociais e que tem como objetivo alcançar uma maior quantidade de informações do objeto estudado. A proposta foi promover uma pesquisa participante para a coleta de dados, em que a pesquisadora reuniu o grupo produtivo e promoveu um diálogo sobre as experiências agroecológicas e seus resultados para a vida das mulheres. Além disso, por participar periodicamente dos trabalhos do grupo, ser parte da comunidade e ser filha de mulheres que integram o grupo, a pesquisadora do mesmo modo é participante da investigação. É válido ressaltar que os nomes das entrevistadas não foram expostos nessa pesquisa para que mantenha-se resguardada as suas identidades.

Os instrumentos de pesquisa utilizados para a compreensão da realidade foram: entrevistas semiestruturadas, roda de conversa e diário de campo. Para tanto, utilizou-se o aparelho de áudio e fotografia (celular), caderno, caneta e diário de campo. Para ser possível a gravação das falas durante as entrevistas com as mulheres, foi feita uma conversa antes para pedir a autorização à coleta e uso dos dados e o preenchimento do termo livre e esclarecido.

Assim, diante do objetivo do trabalho que busca analisar as relações que envolvem o processo de transição agroecológica e o empoderamento das mulheres, no decorrer do texto problematizamos a respeito das relações que abrangem o modelo agroecológico, sua importância para a reestruturação do conjunto sociopolítico, cultural e produtivo, abordando também a questão de gênero na sociedade, e sobre isso, trataremos de como se davam essas relações, no trabalho, na família ou em qualquer outro aspecto que envolva a mulher e as problemáticas em torno disso. Para além desses fatores, ainda abordaremos as implicações que este processo trouxe, perdurando na atualidade, dentro dos espaços comunitários. Por fim apresentaremos a análise dos efeitos da existência de grupos produtivos e da transição agroecológica em uma perspectiva de contribuição e fortalecimento da mulher para gerar a sua autonomia por meio da renda, do conhecimento e do trabalho coletivo fora do âmbito doméstico.

\section{A Agroecologia como modelo de produção contra-hegemônico ao agronegócio}

Com o cenário pós Segunda Guerra Mundial no século XX, inicia-se em diversos 
países periféricos da América Latina, em função do financiamento bancário, um processo que ficou conhecido como Revolução Verde trazendo uma nova forma de produção agrícola que tem como princípio servir como mecanismo de manutenção do sistema econômico capitalista por meio da inserção da mecanização das atividades produtivas, o uso intensivo de adubos químicos, herbicidas e sementes geneticamente modificadas, maximizando da produção agrícola (ALTIERI, 1998).

Segundo Altieri (1998), o novo modelo de produção desencadeou uma série de crises sociais, ambientais e econômicas oriundas da intensificação da concentração de riquezas e de terras, que perduram até a atualidade, repercutindo em inúmeras implicações que impactam diretamente e, principalmente o campo, resultando no aumento do êxodo rural e de conflitos em vários aspectos. No que se refere às questões ambientais, há a depredação da natureza, com a contaminação do solo, de alimentos e escassez dos recursos naturais. No sentido econômico, há redução da mão de obra por meio da substituição dos trabalhadores por maquinários, ocasionando a redução da renda e impactando o desenvolvimento social da população.

No Brasil, a partir de meados da década de 1980, com a inviabilização dos subsídios ao crédito, tornam-se gradativamente mais visíveis as consequências menos gloriosas do padrão de agricultura introduzido com a Revolução Verde (ALTIERI, 1998, p. 03).

Diante desse cenário de tantas crises e retrocessos consequentes deste molde, entre essas e outras razões, amplia-se as discussões em torno de novas propostas de modelos alternativos de produção agrícola, assim como ainda cita o autor: "(..) experiências "diferentes" daquela do padrão proposto pelo ideário da Revolução Verde" (ALTIERI, 1998, p. 03). Propostas e experiências que atraíram bastante a atenção de estudiosos da área das ciências agrárias e outras esferas, como o governo e agricultores.

Toda a discussão em torno dessas novas formas de praticar e viver a agricultura insere-se nestes últimos anos no debate da sustentabilidade do desenvolvimento, indicando, genericamente, um objetivo social e produtivo, qual seja, a adoção de um padrão tecnológico e de organização social e produtiva que não use de forma predatória os "recursos naturais" e tampouco modifique tão agressivamente a natureza, buscando compatibilizar, como resultado, um padrão de produção agrícola que integre equilibradamente objetivos sociais, econômicos e ambientais (ALTIERI, 1998, p. 04).

Assim, as discussões em torno dessas novas experiências aumentaram de tal forma que já se encontram núcleos de debate em que os movimentos sociais do campo 
se tornaram protagonistas desse processo como o MPA (Movimento dos Pequenos Agricultores) e MST (Movimento dos Trabalhadores Sem Terra).

Dessa forma, a Agroecologia pode ser definida como um conjunto de estratégias e princípios que visam à vinculação das relações com a natureza, de tal forma em que ela mostre os caminhos, se fazendo bem menos agressiva ao meio ambiente, sendo uma forte expressão sócio-política, promovedora da inclusão social e do melhoramento econômico de quem adota este modelo, visando o desenvolvimento rural de maneira sustentável, a busca pela autonomia de homens e mulheres, sendo um modelo alternativo que vai contra os ideários do agronegócio (CAPORAL; COSTABEBER, 2004).

Diante destas definições, é possível pensar a Agroecologia como um claro modelo de agricultura alternativa que se faz necessária para a modificação do setor de produção de alimentos no mundo, principalmente nos locais mais impactados pela hegemonia do agronegócio, sistema este que reflete diversas problemáticas que atingem de forma muito direta as relações sociais nos aspectos que vão desde questões econômicas como também ambientais.

\begin{abstract}
A análise do atual sistema agrícola e alimentar baseado no Agronegócio revela que os problemas sociais, econômicos e ambientais por ele causados demonstram sua insustentabilidade, tendo em vista que o nível de impactos negativos gerados (exclusão social, poluição do ar, dos solos, das águas, animais e pessoas, pobreza rural, concentração da renda e da terra) é muito superior aos impactos positivos (aumento da produtividade agrícola) (GONÇALVES; ENGELMANN, 2009, p. 02).
\end{abstract}

Esta análise nos remete a uma avaliação do principal modelo de produção representado pelo sistema capitalista, provocando um questionamento de como acontece a sua atuação, quais as suas diretrizes e, principalmente, qual o público que o agronegócio mais atende. Será mesmo que o principal objetivo deste é acabar com a fome no mundo, como se justificou durante a Revolução Verde? Mas, olhando os aspectos da realidade que nos cerca, é possível observar que, como citam os autores, o sistema de produção de alimentos através do agronegócio vem apresentando mais desvantagens em todo o conjunto social do que pontos positivos, já que as principais características deste sistema é a produção em larga escala dentro de vastos territórios, gerando muita concentração de terra no domínio de poucos, causando também a acumulação de riquezas, a produção de alimentos ou quaisquer outros a base de produtos químicos que são prejudiciais à saúde humana e do meio ambiente, fauna e Revista de Políticas Públicas e Gestão Educacional (POLIGES) - UESB-Itapetinga. ISSN: 2763-5716Ano 2020, Volume 1, número 1, set. - dez. de 2020. 
flora.

Uma das propostas mais avançadas para superar a agricultura atual é a Agroecologia, forma de produção agrícola centrada na produção sustentável, incorporadora de conhecimentos tradicionais e técnicos, que valoriza não só o meio ambiente e a produção sustentável, mas a comercialização solidária que reforça as relações tanto dos produtores entre si, como destes para com os consumidores através de novas relações de mercado (GONÇALVES; ENGELMANN, 2009, p. 02).

A Agroecologia é uma das alternativas mais avançadas para superar o processo hegemônico do agronegócio e, nesta tentativa, muitas organizações, movimentos, comunidades camponesas, famílias e estudiosos vêm aderindo uma compreensão sobre a transição agroecológica, desenvolvendo os caminhos contra- hegemônicos diante da agricultura convencional e recriando a ideia de agricultura sustentável, envolvendo não só a dinâmica de produção, mas toda a relação com a natureza, homens e mulheres. Nesta perspectiva, a proposta da Agroecologia nas esferas do campesinato vem como verdadeira transformação, se dando aos poucos nos espaços coletivos trabalhados não só pelas questões relacionadas ao campo de produção, mas também, a discussão de desenvolvimento, geração de renda, sustentabilidade, viabilidade social através da inclusão de todos.

Portanto, ao mesmo tempo em que é uma fonte de alimentos saudáveis e sustentáveis, o modelo de agricultura alternativo definido como Agroecologia torna-se uma bandeira de luta que vai contra os ideários da produção convencional, visando a transformação de todo o conjunto da sociedade e da natureza e impactando no desenvolvimento de um projeto de país e de nação.

\section{A potencialidade da transição agroecológica no semiárido baiano}

O semiárido é fortemente caracterizado pelo bioma que cobre maior parte de seu território, a Caatinga. Esta é endêmica, ou seja, se faz presente exclusivamente no Brasil e apresenta diversos aspectos que compreendem as condições climáticas e o tipo de vegetação, além da fauna e flora nativos e adaptados com alto potencial às características desta região. Outro aspecto que caracteriza o semiárido é o baixo índice pluviométrico, com poucas precipitações, o que causa um déficit hídrico elevado durante longos períodos anuais. Entretanto, isso não significa falta de água, pois ainda chega ser considerado o semiárido mais chuvoso do planeta (CONTI; SCHROEDER, 
2013).

Diante das adversidades que esta região apresenta, sejam climáticas e/ou políticas sobre as formas de lidar com as secas que a castigam, pois apesar de haver alguns programas desenvolvidos especificamente para o semiárido que levem em consideração suas características, suas necessidades como os programas sociais de captação de água, produção de alimentos, de crédito e financiamento para agricultores, essas ações ainda não são capazes de envolver em sua totalidade os diversos sujeitos sociais locais e, consequentemente, potencializar a convivência com o semiárido há uma riqueza imensurável com relação às estratégias de sobrevivência das famílias que tiram seu sustento e os recursos necessários para a manutenção e reprodução da vida. Muitas formas encontradas para garantir esse sustento vem do próprio bioma, com a produção de animais de pequeno, médio e grande porte, utilizando as práticas de manejo racional da caatinga para pastoreio extensivo e outras atividades produtivas, como o extrativismo de plantas nativas.

Para as diferentes comunidades rurais da Caatinga, esse uso direto dos recursos naturais é um dos aspectos mais positivos da biodiversidade. Muitas vezes, diferentemente das pessoas que vivem nas grandes cidades, famílias que vivem no meio rural dependem do meio ambiente e utilizam-no diretamente, pois extraem recursos para a sua alimentação, construção de casas e cercas, cura de doenças, fabricação de ferramentas, entre outras funções (ALBUQUERQUE et al, 2010, p.13).

Essa ligação direta que as comunidades camponesas que vivem no semiárido têm com a natureza é também considerada uma forte expressão de desenvolver a transição agroecológica em seus mais variados aspectos, seja na forma de produzir ou de lidar com o âmbito social e político, envolvendo as formas de se organizar enquanto comunidade. Deste modo, é possível visibilizar a aproximação e a compreensão que essas comunidades têm sobre a importância da preservação da natureza em meio ao contexto de produção e organização conservando também os saberes empíricos, valorizando a importância que isto tem para o fortalecimento da região.

São nestes lugares onde as experiências agroecológicas são efetivadas dentro de pequenos espaços de vivência e interação coletiva, como grupos produtivos e quintais agroecológicos familiares, principalmente entre mulheres camponesas, que com base nos princípios e no desenvolvimento ecológico de produção, consolidam a devida ocupação de espaço, ganhando destaque em muitas atividades que por vezes só se viam homens, com isso modificam uma estrutura machista fortemente enraizada 
nas comunidades.

Algumas estratégias de manutenção da vida das famílias no semiárido também envolvem as formas de produção e geração de renda através do Agroextrativismo, a produção tradicional sertaneja que se caracteriza pelo beneficiamento de recursos extraídos da própria Caatinga, e muitas vezes, através dos trabalhos desenvolvidos dentro de grupos produtivos, que tem como principal objetivo trabalhar a autonomia dos sertanejos por meio da economia solidária. Estas práticas em muitos casos se concretizam como um sistema agroecológico desenvolvido pelos camponeses, compreendendo também a convivência com o Semiárido.

A convivência manifesta uma mudança na percepção da complexidade territorial e possibilita resgatar e construir relações de convivência entre os seres humanos e a natureza, tendo em vista a melhoria da qualidade de vida das famílias sertanejas (CONTI; SCHROEDER, 2013, p. 27).

Desta forma, entende-se que a ligação entre as dinâmicas produtivas, a criação ou modificação das formas de manutenção da vida determinaram a organização de cada espaço de acordo com seus recursos disponíveis e as estratégias pensadas e utilizadas para aproveitá-los. É justamente nesta perspectiva que esta pesquisa se direciona para o estudo das relações na construção de uma nova forma de vida em um âmbito comunitário, ligando principalmente a Agroecologia, o campesinato e o gênero nesta relação.

\section{A contribuição das práticas agroecológicas no processo de construção do empoderamento de mulheres camponesas}

Desde sempre a mulher assume papéis de extrema importância para o desenvolvimento da sociedade, e essa função não está ligada somente aos aspectos que a muito tempo foram designados a elas, de reprodução cuidado maternal e do lar, e sim na condução de situações determinantes no conjunto social no qual ela está inserida, seja nas questões políticas, econômicas, organizativas e socioculturais, a mulher sempre vai estar presente e de alguma forma sua atuação será decisiva para determinado processo.

Uma das questões incisivas dentro do conjunto de relações sociais é a divisão de trabalho de acordo com o gênero. Na construção social, a mulher esteve numa condição de subalternidade, ou seja, sob as ordens de outros, na maioria das vezes ao poder do homem, e sendo considerada inferior em vários aspectos, como o da força

Revista de Políticas Públicas e Gestão Educacional (POLIGES) - UESB-Itapetinga. ISSN: 2763-5716Ano 2020, Volume 1, número 1, set. - dez. de 2020. 
física, na sua capacidade de comando, inteligência e autonomia. Apesar disso, partimos da compreensão de que o ser mulher não é uma condição igual para todas: há diferenças entre ser mulher negra, branca, camponesa, de periferia. Essas diferenças incidem nos modos e condições de vida dessa mulher nos espaços em que transita.

O conceito de gênero é uma construção social e histórica a partir da qual nascem as relações sociais construindo as relações de poder que, dentro do mercado de trabalho, acarretam no acesso diferenciado de homens e mulheres aos recursos e capacitações (SILVA; OLIVEIRA, p. 01).

A divisão de gênero no trabalho é evidente e está presente em quase todos os espaços, causando um tratamento muito diferenciado a respeito das funções exercidas e a quantidade a se receber do salário, por exemplo. Neste aspecto, os homens chegam a ganhar mais que as mulheres, mesmo cumprindo a mesma função no trabalho. Segundo dados de 2019 do IBGE, as mulheres ganham 20,5\%menos que os homens. Todas estas interpretações e ações são consequências de um processo de enraizamento do patriarcado e da cultura machista impregnada em todo o mundo, desde a formação das sociedades existentes.

$\mathrm{Na}$ esfera do campesinato, a situação da discriminação relacionada ao gênero não é diferente, principalmente dentro das famílias, devido a ideia de que o homem deve sair para trabalhar e sustentar a família, enquanto a mulher fica em casa cuidando dos filhos e dos afazeres domésticos. É como aponta Melo (2002):

A mulher, embora participe ativamente das atividades agrícolas familiares, é considerada como ajudante da família, trabalha de forma gratuita, sem ter o reconhecimento do seu trabalho pela família e, até por ela, do mesmo modo que pela esfera pública (MELO, 2002, p. 01).

A prática de desconsiderar a participação feminina nas atividades e a desvalorização de sua capacidade produtiva prejudica a mulher em muitos aspectos, principalmente na sua integração nos programas de desenvolvimento rural, o que evidencia a lógica da divisão sexual do trabalho.

A invisibilidade da atuação feminina nos trabalhos produtivos consolida essa desigualdade, ou seja, apesar da mulher frequentar e contribuir nas atividades em que o marido ou filhos desenvolvem na agricultura, ela não é considerada uma protagonista, e sem ser reconhecida como parte importante do trabalho não recebe remuneração, pois " $81 \%$ das mulheres envolvidas em atividades agrícolas não recebem nenhum tipo de compensação financeira pelo seu trabalho" (MELO, 2002). Ainda, aponta-se que 
"nas principais alternativas que têm permitido a reprodução do campesinato brasileiro, recorrentemente o papel da mulher é subestimado, a tal ponto que aparece como negado" (SARTRE, 2013, p. 107). Esta situação acaba se tornando um mecanismo que torna a mulher cada vez mais dependente no aspecto financeiro, reprimindo-a em diversas situações, inclusive na criação de sua autonomia perante as próprias decisões.

A figura do pai como representação principal da agricultura familiar reflete a cultura que secularmente elegeu o masculino como responsável pelo exercício das atividades desenvolvidas "fora do espaço da casa", uma vez que o âmbito de trabalho "da casa" é o "lugar da mulher". No geral, essa ideologia existe, mesmo quando a participação da mulher no mundo do trabalho é cada vez mais crescente (MELO, 2002, p.05).

A condição da mulher em um estado de reconhecimento da sua participação aos poucos vem sendo modificada, graças a luta que estas passaram a desempenhar devido às consequências da trajetória desoladora formulada pelo conjunto da sociedade patriarcal. É uma luta que surge através da integração das mulheres como um movimento organizado.

O aparecimento dos movimentos de mulheres rurais no Brasil remonta aos anos 1980, com as primeiras manifestações por seu direito à sindicalização, de forma independente de pais, irmãos ou maridos. Vivia-se um período de ressurgimento dos movimentos sociais após 20 anos de ditadura militar. Movimentos feministas urbanos reivindicavam direitos para as mulheres e ecos destas questões chegariam às mulheres rurais, que se organizavam em grupos, com apoio de setores das igrejas progressistas, como parte da proposta de disseminação das comunidades eclesiais de base. Suas primeiras lutas foram pelo reconhecimento da sua profissão enquanto agricultoras e por direitos decorrentes desse reconhecimento (SILIPRANDI, 2013, p. 132).

Estas ascensões deram base para a luta que as mulheres vêm travando para desconstruir toda forma de discriminação e desigualdade de gênero e um dos pilares no qual as camponesas vem se integrando é a dinâmica do movimento agroecológico, dentro dos seus próprios espaços de vivência, contribuído também para a expansão das ideias que envolvem essa prática. Por meio de experiências agroecológicas mulheres têm conquistado formas de empoderamento e autonomia, já que este é um modelo alternativo que propõe dialogar não só as dinâmicas de produção, mas também, envolver a estrutura social na qual estamos inseridos, discutindo formas de reestruturação, inclusive relacionado a desigualdade de gênero, sendo ainda necessário que se abram mais discussões a respeito dessa questão e outros elementos importantes e ainda não questionados.

Nesta perspectiva, a Agroecologia se faz uma ferramenta importantíssima para Revista de Políticas Públicas e Gestão Educacional (POLIGES) - UESB-Itapetinga. ISSN: 2763-5716Ano 2020, Volume 1, número 1, set. - dez. de 2020. 
compreender este processo de exclusão e desvalorização da mulher enquanto participante ativa no campesinato, assim como também é essencial para modificar a estrutura patriarcal neste meio.

\begin{abstract}
Entre os fatores que favorecem o reconhecimento das mulheres nesses sistemas de produção, podemos citar o destaque que é dado às atividades tradicionalmente desenvolvidas pelas mulheres dentro da produção familiar (hortas, pomares, pequenos animais, transformação caseira de produtos); a mudança de atitude que é requerida, com relação ao meio natural e às pessoas, em uma perspectiva colaborativa e de valorização da contribuição de todos para o sucesso dos empreendimentos; a necessidade de integração do conjunto de atividades da propriedade (visão sistêmica); a possibilidade de maior participação das mulheres em atividades fora do âmbito doméstico (cursos, eventos, feiras etc.); além do aumento da renda obtida pelas mulheres com seus produtos, advinda da comercialização em nível local e regional (SILIPRANDI, 2013, p. 329).
\end{abstract}

O movimento de organizar-se em coletivos para produção agroecológica, vendas em cooperativas, fazer parte da Economia Popular e Solidária, se integrar dentro das comunidades para desenvolver um trabalho produtivo, tudo isso e vários outros fatores vem contribuindo no processo de criação da autonomia das mulheres, refletindo principalmente no aspecto econômico dessas. Atualmente, existem diversas instituições que têm como principal atuação dar apoio e valorizar os produtos oriundos do campesinato, especialmente de origem agroecológica. Nesta perspectiva, as comunidades rurais se envolvem nos projetos desenvolvidos pelas instituições, muitos desses projetos estão ligados à produção de alimentos e é aí onde as mulheres passam a se integrar. Em grupos produtivos, as camponesas passam a desenvolver seus trabalhos de maneira autônoma, coletiva, fora do âmbito doméstico, no entanto, gerando jornadas duplas ou triplas de trabalho, mas gerando sua própria renda e ainda trabalhando com base em princípios sustentáveis e politicamente justos.

O grupo produtivo solidário de beneficiamento de frutas, Mulheres de Esperança da comunidade de Salgado é constituído por doze mulheres que desenvolvem seus trabalhos com frutas nativas da Caatinga e com o processamento da fécula de mandioca na casa de farinha local. A principal base organizacional da comunidade é a associação comunitária, onde a maior parte dos moradores são integrados e com isto, está sempre buscando propostas de desenvolvimento para a localidade. A associação foi uma atuante fundamental no processo de construção da unidade produtiva, pois ela doou o espaço para a estruturação da cozinha e também um galpão para armazenar os 
produtos.

O ano de fundação do grupo produtivo foi 2012, com a articulação da Associação comunitária do Povoado Salgado e Fazenda Silgueira e da ARESOL (Associação Regional dos Grupos Solidários de Geração de Renda). Ele surgiu através do projeto Fundo Rotativo Solidário do GREPS (Grupo Regional de Economia Popular e Solidária) e do projeto Solidariedade e Cidadania Sertaneja. Estes têm como objetivo a melhoria da renda das famílias do campo, o aproveitamento de frutas da caatinga (acerola, maracujá do mato e umbu), a garantia de uma alimentação saudável para as famílias e o desenvolvimento da região. O valor recebido do projeto para a estruturação da unidade produtiva foi de $R \$ 13.797,70$, sendo o recurso usado para a construção de uma cozinha e banheiro e a compra de equipamentos para o beneficiamento das frutas.

Com o desenvolvimento da produção, o grupo começou a acessar políticas públicas como o PAA (Programa Aquisição de Alimentos) e PNAE (Programa Nacional de Alimentação Escolar) para viabilizar e fazer o escoamento da produção, tudo isso através da ARESOL, que fez com que o grupo tivesse acesso a estes recursos. Entretanto, a venda dos produtos para o PAA aconteceu somente até o ano de 2014, com isto a unidade passou a disponibilizar apenas para o PNAE e o ponto de vendas da agricultura familiar da cidade de Monte Santo, "Monte Sabores", criado pela ARESOL com o objetivo de garantir um ponto fixo onde os grupos possam escoar suas produções, caso as políticas públicas venham a faltar, assim como aconteceu com o PAA.

Atualmente, o grupo se encontra bem estruturado, constituído por mulheres que buscam desenvolver um trabalho digno, que garanta a sua soberania a partir da organização e trabalho coletivo através de uma dinâmica de produção baseada em uma economia justa, solidária e ecologicamente correta, voltada aos princípios agroecológicos dentro de um processo de transição, visando a reconstrução dos aspectos que caracterizam o trabalho do grupo na esfera social e produtiva.

As integrantes do grupo produtivo Mulheres de Esperança são mulheres de baixa renda, algumas contam com aposentadoria e trabalho como diaristas, mas no geral, todas também desenvolvem suas atividades na roça, juntamente com seus maridos ou mesmo sozinhas. As labutas diárias incluem os trabalhos domésticos, cuidado com a casa, com os filhos e as demandas dos trabalhos fora do âmbito familiar, isso inclui contribuições na igreja, associação comunitária e o próprio grupo produtivo. Em resumo, isso remete a avaliação da multiplicidade de tarefas que estas mulheres se 
dedicam a desenvolver todos os dias.

A dinâmica de produção através da experiência de grupos é algo presente em muitos locais e dentro das comunidades rurais isso vem sendo intensificado por meio de ações organizativas de coletivos que se preocupam com o desenvolvimento social, econômico, cultural e político desses meios. As mulheres da comunidade Salgado são exemplos de como a existência dos grupos interferem no desenvolvimento social destas, principalmente através da maneira em que elas produzem e como se organizam internamente.

\begin{abstract}
Aliada ao campesinato, a estratégia de desenvolvimento rural da Agroecologia possibilita a criação de vários espaços de trabalho, coletivos e solidários que visam, além da inserção econômica por meio de mercados curtos, minimizar a penosidade do trabalho no campo e promover a preservação do meio ambiente, ao mesmo tempo em que busca integrar, dentro dos processos produtivos, todos os seus membros: homens, mulheres e jovens (SILVA, 2016, p. 119 apud Sevilla -Guzmán \& Montiel, 2009). Sobre esta experiência o Grupo Mulheres de Esperança traz como positivo muitos efeitos do grupo, assim como afirma uma entrevistada ao dizer: "Pra mim foi bom, a experiência foi bom, teve conhecimento dentro do próprio grupo, o conhecimento das próprias pessoas, apesar das diferenças, cada um reage de uma maneira" (Camponesa 02).
\end{abstract}

A perspectiva de lidar com um grupo produtivo remete a uma situação de aprendizado constante, já que através da interação de todas, há sempre a partilha do conhecimento. Além disso, a prática do trabalho produtivo como forma de empreendimento necessita de aprimoramento, por isso estas mulheres estão sempre participando de cursos, palestras, formações sociopolíticas que abrangem todo o contexto em que elas estão diretamente inseridas, tanto na perspectiva de produção, quanto no aspecto cultural do meio de vivência e das formas em que esse vem se estruturando, e sobre isso podemos citar a relação de gênero no ponto de vista das próprias mulheres, como elas se enxergam e o que pensam sobre isso.

É neste sentido que as mulheres do grupo destacam a importância deste, principalmente pelo fato dele ter sido uma fonte de aprendizados diferentes e inovadores: "Eu também não tive dificuldade não, pra mim foi muito bom, a gente aprendeu muitas coisas" (Camponesa 03). Outra entrevistada traz também um ponto importante sobre as responsabilidades que elas passaram a ter a partir do surgimento do grupo em suas vidas: "Pra mim é uma experiência que você passa a ter mais responsabilidade das coisas, a assumir os horários, dia certo e os deveres".

Revista de Políticas Públicas e Gestão Educacional (POLIGES) - UESB-Itapetinga. ISSN: 2763-5716Ano 2020, Volume 1, número 1, set. - dez. de 2020. 
(Camponesa 01).

A consolidação de um trabalho coletivo através dos grupos produtivos fortalece a ideia de cooperativismo e economia solidária que Singer (2002) conceitua explicando que "a empresa solidária é basicamente de trabalhadores, que apenas secundariamente são seus proprietários. Por isso, sua finalidade básica não é maximizar lucro, mas a quantidade e a qualidade do trabalho." Com isto, essa consolidação da qual nos referimos abrange aspectos não só produtivos, mas questões sociais, políticas e organizativas, como neste caso, onde o grupo, com bases no cooperativismo se liga às ideias de reestruturação do seu espaço de vivência, buscando e transformando os mecanismos que possibilitam a abertura das discussões referente ao modelo de produção e a atuação das mulheres enquanto protagonistas de um projeto que visa a inserção dessas no mercado de trabalho a partir das suas próprias produções, assim, criando possibilidades e alicerçando o empoderamento feminino na comunidade. Este pode ser entendido:

A partir de uma perspectiva em que os indivíduos, organizações e comunidades coletam recursos de forma a terem voz, visibilidade, influência e capacidade, tanto de ação, quanto de decisão, ou seja, poderem controlar os temas que afetam suas vidas. Sendo assim, desenvolve-se um processo de ampliação da cidadania que congrega dimensões de igualdade social e reconhecimento das diferenças, um processo maleável e inclusivo (SIMON; BOEIRA, 2017, p. 538).

Além do que o grupo destaca sobre a importância do trabalho coletivo, as mulheres trazem também relatos a respeito das dificuldades enfrentadas, pois a consolidação dessas atividades não se dá apenas de forma positiva, assim como diz uma entrevistada em uma visão particular: "Eu pra mim não ajudou muito não viu, os primeiros anos sim até que melhorou bastante, mas de uns dois anos pra cá" (camponesa 01).

Outra entrevistada também ressalta que "Chegaram a ganhar muito dinheiro, principalmente quem tinha suas tapiocas que vendia e a prefeitura comprava mais, de uns tempos pra cá a prefeitura quase não compra mais os nossos produtos" (camponesa 03). Ou seja, apesar do grupo se destacar em suas atividades de produção, a falta de apoio vindo de órgãos públicos interfere no desenvolvimento deste, o que resulta em uma certa desmotivação por parte das camponesas, já que sem recurso as dificuldades para lidar com o processamento de todo trabalho se torna mais complicado. A prefeitura municipal, por exemplo, poderia servir como um suporte essencial para a maior valorização do trabalho, disponibilizando recursos para investir

Revista de Políticas Públicas e Gestão Educacional (POLIGES) - UESB-Itapetinga. ISSN: 2763-5716Ano 2020, Volume 1, número 1, set. - dez. de 2020. 
no empreendimento, apoiando a comercialização e a exposição dos produtos, no entanto, existe uma grande falha neste aspecto, sendo isto uma das maiores insatisfações das mulheres do grupo produtivo.

Contudo, a base dos trabalhos produtivos, ou mais especificamente, a dinâmica que estas utilizam para produzir, na avaliação das camponesas do Grupo Mulheres de Esperança é algo que contribui na valorização por grande parte do público consumidor, pois são produtos feitos a partir dos recursos extraídos do próprio trabalho dessas camponesas. Dos pomares de frutíferas tiram a acerola e na caatinga, com a prática do extrativismo, o umbu e o maracujá, além da farinha, fécula e beijus que são processados e feitos com a produção de mandioca dos roçados das próprias famílias.

Pra mim também foi uma das melhores coisas, foi uma das coisas que a gente aprendeu aqui depois desses grupos foi as frutas nativas, que são o umbu, a acerola, o maracujá, a gente aprendeu a cuidar dessas plantas que a gente não dava a mínima pra elas né, e hoje cuida e tem o maior valor (Camponesa 03).

Na perspectiva da camponesa entrevistada, o surgimento do grupo foi essencial para que elas pudessem compreender a importância do aproveitamento das frutas nativas da Caatinga, principalmente para fins de produção e comercialização, o que neste caso se tornaria uma das principais fontes de renda para elas. Além disso, trouxe também uma nova ideia sobre a segurança dos alimentos que estão sendo processados e a forma que isto se dá, tanto para elas que produzem quanto para quem compra e consome, assim como relata uma das entrevistadas: "Pra mim eu acho importante, porque pelo menos o que você usa, por exemplo um suco você toma sem susto, você sabe que realmente é natural, nada tóxico." (Camponesa 01).

Para as integrantes do grupo existe uma boa aceitação dos produtos, embora não seja no geral, pois, segundo elas, na própria comunidade, local onde todos conhecem a procedência do que é feito, tem uma certa rejeição, exceto na questão dos beijus, assim como é colocado por uma das camponesas:

Pra mim a qualidade é boa, agora a aceitação que não é tanto, mais dos bejus né, a aceitação dos bejus foi melhor do que do restante dos produtos, mas pra mim todos tem qualidade, principalmente na comunidade que a aceitação foi bem pouca (Camponesa 03).

Diante do todo o contexto que estas mulheres camponesas já vivenciaram, numa perspectiva de produção, a visão que elas passaram a ter a partir do trabalho desenvolvido no grupo produtivo remete a uma lição que é compreendida muito bem 
por elas baseando-se nos princípios da Agroecologia, o que fez com que estas mudassem certos comportamentos da comunidade, tanto no modo de pensar quanto no de praticar a atividade produtiva. Essa visão é bem destacada no trecho da entrevista de uma camponesa quando ela dá o exemplo da duração de um coentro que é comprado na feira ou plantado no próprio quintal:

As coisas naturais são diferentes, eu vejo os coento, eu ia comprando coento, alface, menina você compra alface na sexta e no sábado tá dilindo, não sei o que eles colocam no alface e coento, e coento em casa você planta e passa semana na geladeira, o coento bom, verdinho e essas coisas chega deli, fica preto, como se desmancha (Camponesa 02).

A situação que a entrevistada coloca é uma grande problemática para a segurança da manutenção da vida de todos, em relação ao acesso a uma alimentação saudável e de qualidade, além da valorização do trabalho produtivo realizado pela comunidade e todo o contexto social que as envolvem, pois trata-se da predominância de um sistema onde só se tem acesso a produtos industrializados, alimentos contaminados com agroquímicos e uma limitação das próprias pessoas em buscarem recursos alternativos, fugindo do convencional imposto pelo agronegócio. Esse contexto engloba praticamente todas as esferas dentro da perspectiva do campesinato, se conectando com as relações políticas, sociais e econômicas, assim como é problematizado por Silva (2016) ao ressaltar que:

A lógica produtivista e mercadológica dominante no processo de modernização do campo, reforçada por políticas neoliberais, além de causar danos ao meio ambiente, modificou os processos de produção e consumo do alimento e aumentou a pobreza e a exclusão social, sendo as mulheres as mais afetadas nesse processo.No entanto, dentro desse cenário, vêm surgindo novas estratégias, como a Agroecologia e a economia solidária, que estão possibilitando às famílias agricultoras camponesas continuar resistindo e existindo no campo,com as mulheres sendo protagonistas dessas políticas alternativas de sustentabilidade (SILVA, 2016, p. 115).

Em relação às mudanças que as mulheres tiveram em suas vidas a partir do surgimento do grupo produtivo e a interação no empreendimento solidário, as camponesas destacam aspectos tanto positivos quanto negativos, bem como já ressaltado anteriormente, a exemplo do que uma das entrevistadas coloca a respeito da renda que muitas vezes não é tão satisfatória o quanto elas esperam "O bom foi porque a gente nunca mais dependeu de pedir dinheiro ao homem, o marido e o ruim é que as

Revista de Políticas Públicas e Gestão Educacional (POLIGES) - UESB-Itapetinga. ISSN: 2763-5716Ano 2020, Volume 1, número 1, set. - dez. de 2020. 
coisas agora estão mais devagar, a gente não recebe mais igual recebia no início" (camponesa 05).

No entanto, outra camponesa já destaca um ponto bastante interessante, ressaltado também por outras mulheres e que há muito vimos discutindo ao longo dos debates nessa pesquisa, a autonomia financeira, uma forte expressão dos frutos do trabalho coletivo dessas camponesas que acaba gerando sua independência. Embora ainda existam dificuldades e a renda adquirida oscile em alguns períodos, pode-se perceber na fala das mulheres que as atividades tiveram resultados positivos, principalmente para a modificação de certos costumes na vida delas, como a dependência do marido: "Antes dependia só dos trocados do marido e hoje não mais, depende do que você vai precisar também, antes dependia pra tudo do marido e agora não" (camponesa 03). Outra ainda destaca com mais autenticidade os resultados do trabalho no grupo produtivo para a vida pessoal dessas mulheres e sua visão positiva sobre isso, apesar das dificuldades:

\begin{abstract}
Mesmo poquinho que a gente recebe, mas a gente tem uma esperança que vai receber aquele pouquinho né, e a ajuda que qualquer coisinha que você precisa pra comprar tinha que ir no marido e às vezes não tinha e agora não, a gente tá ajudando ele né, tá ajudando o marido porque você ta dependendo do seu dinheirinho (Camponesa 06).
\end{abstract}

Ainda nesta perspectiva de autonomia, aproveita-se a oportunidade para abranger o debate sobre a participação dos homens nos trabalhos do grupo, o ponto de vista das mulheres em relação a isso e os pontos de vista a respeito das formas de divisão do trabalho. Ao perguntar as mulheres sobre o que elas acham da presença do homem no grupo elas respondem que é importante pois eles podem assumir algumas tarefas que requerem mais peso e muitas vezes a mulher não pode executar, segundo elas por não terem a mesma força que eles. Também ressalta a questão da saúde das mulheres, pois segundo elas, algumas no podem se sujeitar a tarefas que necessitam de muito esforço físico, como o de pegar caixotes carregados, baldes, etc. mas, mesmo assim, a capacidade que elas têm de desenvolverem tranquilamente a atividade que poderia ser dirigida ao homem não é subestimada:

Muitas vezes a gente tem a capacidade de fazer aquilo, mas porque tem um homem ou dois aí isso é serviço pra homem, só num sei o que é certo pra mulher é ela pegar peso né, muito peso, às vezes tem uma só que tem coragem de pegar, mas as zotas já frea porque não quer pegar peso, essa questão aí acaba a gente dependendo de um homi, mas tirando disso ai, qualquer mulher tem a capacidade de enfrentar (Camponesa 07).

Revista de Políticas Públicas e Gestão Educacional (POLIGES) - UESB-Itapetinga. ISSN: 2763-5716Ano 2020, Volume 1, número 1, set. - dez. de 2020. 
Mas, há também aquelas que discordam e acham que a presença de homens nos trabalhos do grupo não influencia tanto, ou seja, as próprias podem realizar todas as atividades.

"É bom sempre ter pra ativar mais a gente, mas a gente mulher hoje em dia já manda no pedaço" (Camponesa 05). O entendimento dessas mulheres a respeito de sua importância, força e visibilidade na sociedade e, principalmente, em seus espaços de vivência já é muito grande e necessário. Estas mulheres passaram a se enxergar enquanto protagonistas de uma ação extremamente significativa e transformadora na comunidade e na vida das mesmas.

Se não tivesse homem no meio era mais uma coisa pra as mulheres mostrar que é capaz de fazer aquilo sem a presença do homem, se um homem pra fazer aquilo o que a mulher faz, ela se encosta, o homem que vai, se não tiver o homem eu tenho certeza que uma das mulher tem a coragem do mermo jeito (Camponesa 07 ).

Elas ainda acrescentam que é importante, porém, se não tiver o homem, as próprias mulheres têm a capacidade de assumir a tarefa "É até bom a participação do homem, mas no causo se não tiver o homem as mulher tem a capacidade também nessa parte” (camponesa 04). Este aspecto é de grande importância para avaliação geral da perspectiva das mulheres a respeito do seu protagonismo e capacidades, pois percebe-se que há o autoconhecimento e compreensão da autossuficiência que o conjunto das mulheres formadas no grupo criaram para se manter em seus trabalhos, demonstrando ainda que elas não precisam ficar esperando a intervenção de um homem para fazer determinadas tarefas, elas mesmas podem construir isso a partir da autonomia criada.

Os avanços e transformações que as integrantes do grupo produtivo "Mulheres de Esperança" tiveram e continuam tendo podem ser observados a partir de suas falas e expressões a respeito das possibilidades que as atividades do empreendimento solidário deram a elas. O fato de ser um grupo composto por mulheres e serem as protagonistas deu total abertura para que elas pudessem assumir como lideranças as rédeas dos trabalhos fora de um âmbito doméstico, por exemplo. Na perspectiva do trabalho produtivo de forma coletiva e assumido por mulheres, remete a uma reflexão a respeito dos locais em que estas podem estar inseridas, mas que pela construção social do patriarcado em todo o conjunto da sociedade, cria-se um certo bloqueio e medo pelas próprias mulheres em ocuparem espaços e criar mecanismos em que 
essas possam se destacar, deixando claro a importância de sua integração e participação, fazendo gerar e enraizar o empoderamento feminino em quaisquer esferas da sociedade, e neste caso, mais especificamente no campesinato.

Empoderamento é, segundo Buendía-Martínez \& Carrasco (2013), o mecanismo pelo qual as pessoas passam a tomar conta de seus destinos, tendo consciência de sua capacidade e competência para administrar seus atos e suas consequências, dando um passo importante na construção de sua cidadania. Favorecem o empoderamento das mulheres o acesso aos recursos produtivos, as mudanças na divisão sexual do trabalho e a valorização social delas (SILVA, 2016, p. 126 apud SILIPRANDI, 2013).

A busca pelo processo de desconstrução da imagem que há muito tempo vem sendo direcionada às mulheres é intensa e está sendo discutida em muitas esferas, sendo isso necessário e urgente. Contudo, o desenvolvimento de uma prática alternativa como ponte e mecanismo fundamental para contribuir neste processo já está sendo elaborada e desenvolvida por estes grupos, e esse estudo de caso é o exemplo disso. A vivência das "Mulheres de Esperança" na comunidade Salgado, dentro da dinâmica produtiva agroecológica e economicamente solidária é a clara demonstração que um novo projeto de sociedade vem sendo construído e muitos já não aceitam este antigo modelo conservador, machista, químico, capitalista e desprezível. A sociedade, ou mais precisamente, as mulheres precisam participar das transformações que fazem parte dos seus modos de vida, precisam fazer parte das decisões, das políticas, da produção, do mercado de trabalho e de tudo que incide em nossas vidas de maneira determinante e isso só é possível com a renovação dos modos de se pensar sobre a diversidade e de se trabalhar junto a ela.

\section{Considerações finais}

Durante a elaboração deste trabalho buscou-se compreender a relação das mulheres camponesas na sua vivência comunitária e familiar numa perspectiva de trabalho coletivo baseado nos princípios de transição agroecológica, enfatizando a questão do empoderamento feminino através dessas práticas e os avanços proporcionados pelos trabalhos desenvolvidos dentro de uma organização produtiva formada pela força de mulheres que buscam a transformação do modo de vida no que tange o aspecto social, cultural, político, financeiro e organizacional de sua localidade.

Considerado a importância da abordagem desse trabalho, foi possível, através da 
busca de dados dentro da comunidade, a compreensão de como se dá o trabalho desenvolvido pelas mulheres do grupo produtivo e como elas vêm conseguindo gerar autonomia e renda, produzindo de forma solidária e de maneira sustentável ao tempo em que resgatam a importância do aproveitamento dos frutos nativos da Caatinga, umbu e maracujá, além da produção de frutíferas, como a acerola em seus quintais e o cultivo familiar da mandioca.

O grupo produtivo Mulheres de Esperança, o qual foi utilizado como estudo de caso, está sendo conduzido, desde sua formação, por mulheres da comunidade Salgado. Embora haja a presença de homens em algumas funções produtivas, o destaque sempre foi das mulheres que se empenharam em fazer desenvolver-se a ideia de um grupo na localidade, assumindo o comando de todas as demandas necessárias desde a parte de processamento dos produtos até a comercialização, tanto para a comunidade, quanto para o público consumidor de fora. A importância que isso tem em todo o contexto de vida dessas mulheres é muito bem destacado quando elas mesmas ressaltam em suas falas, apresentadas ao longo deste trabalho as mudanças positivas e negativas que o grupo trouxe.

Considerando esses dois aspectos, avaliou-se que a partir da experiência do grupo, as mulheres passaram a ter mais autonomia, principalmente financeira, gerando através de seus trabalhos uma renda significativa que contribui em suas finanças dentro de casa, sem precisar totalmente de seus maridos para adquirirem o que desejam. Além disso, os avanços no conhecimento dessas mulheres diante dos assuntos relacionados à questão de gênero, produção, entre várias outras questões foi outro ponto de extrema pertinência para a melhor compreensão das mudanças no empreendimento retratadas nesta pesquisa. Entretanto, é importante frisar que essas mulheres também passam por grandes dificuldades e desafios em relação ao trabalho que essas movem, assim como as entrevistadas ressaltam na questão financeira e as demandas que às vezes são muitas e nem sempre é possível dar conta, mas elas continuam firmes e isso demonstra ainda mais a resistência e insistência para que os frutos desse trabalho somem cada vez mais.

Diante disso, avalia-se que o trabalho produtivo e a Agroecologia são pontes importantes para o avanço da autonomia de mulheres que buscam mudar suas formas de vida, também no que se relacionam as mudanças na forma de produzir e de lidar com a natureza, buscando sempre alternativas ecológicas que não agridam o meio ambiente e tragam possibilidades de soberania alimentar. Portanto, o protagonismo 
dessas mulheres torna-se essencial para a consolidação desse processo.

\section{Referências}

ALTIERE, Miguel. Agroecologia: A dinâmica produtiva da agricultura sustentável.4.ed. Porto Alegre: UFRGS. 2004

ALTIERE, Miguel. Agroecologia: Bases científicas para uma agricultura sustentável. 3. ed. São Paulo, Rio de Janeiro. Expressão Popular, 2012

CAMPOS, Carlos Humberto et al. Convivência com o semiárido brasileiro: Autonomia e protagonismo social. Brasília: IABS, 2013

CAPORAL, Francisco Roberto; COSTABEBER, José Antônio. Agroecologia: Alguns conceitos e princípios. Brasília: EMATER, 2004

FELCHER, Carla; FERREIRA, André Luís; FOLMER, Vanderlei. Da pesquisa-ação à pesquisa participante: discussões a partir de uma investigação desenvolvida no facebook. Rev. Experiências em Ensino de Ciências, v.12, n. 7, p. 1- 18, 2017.

GONÇALVES, Sérgio; ENGELMANN, Sandra Andreia. A Agroecologia e a reestruturação do desenvolvimento rural. Rev. Geografia Agrária, v. 4, n. 8, p. 29 59. 2009.

MACHADO, Maíra Rocha (org). Pesquisar empiricamente o direito. São Paulo: REED - Rede de pesquisa empírica em direito, 2017

NEVES, Delma Pessanha; MEDEIROS, Leonilde Servola (org). Mulheres Camponesas: Trabalho produtivo e engajamentos políticos. Niterói: Qualidade, 2013.

SILIPRANDI, Emma Cademartori. Agroecologia, Agricultura Familiar e Mulheres Rurais.Rev. Bras. Agroecologia, v.2, n.1, fev. 2007. Disponível em: <file:///C:/Users/User-JOTI/Downloads/6427-1-26432-1-10-20070427.pdf>. Acesso em: 13 de ago. 2019.

SILVA, Amanda Salles; OLIVEIRA, Bianca Barbosa. O empoderamento da mulher através da economia solidária enquanto alternativa para emprego e renda. In: CONGRESSO INTERNACIONAL DE ECONOMIA POPULAR E SOLIDÁRIA E DESENVOLVIMENTO LOCAL, diálogo Brasil Cuba, 2016, Feira de Santana. Incubadora de Iniciativas de Economia Popular e Solidária da UEFS, 2016.

SILVA, Flávia Regina Fernandes. Gênero, Agroecologia e economia solidária: estudo de caso do grupo de mulheres do Acampamento Recanto da Natureza em Laranjeiras do Sul - PR. Rev. DMA - Desenvolvimento e Meio Ambiente, Paraná, v. 39, p. 18, dez. 2016. 
SIMON, Vanêssa Pereira; BOEIRA, Sérgio Luis. Economia social e solidária e empoderamento feminino. Rev. Ciências Sociais Unisinos, São Leopoldo, v. 53, p. 532 - 541, dez. 2016.

SINGER, Paul. A recente ressurreição da economia solidária no

Brasil.Disponível em: <http://base.socioeco.org/docs/ecosolv2.pdf\#page=4> Acesso em: 14 de ago. 2019.

\section{Carina de Moraes Pereira Brito}

Tecnológa em Agroecologia pela Universidade Federal do Recôncavo da Bahia em parceria com Escola Familia Agricola do Sertão - EASE e Programa Nacional de Educação na Reforma Agrária - PRONERA, Brasil. Correio eletrônico: carinamsba27@gmail.com.

\section{Priscila Brasileiro Silva do Nascimento}

Doutorado em Educação e Contemporaneidade pela Universidade do Estado da Bahia - UNEB; Docente da Universidade Federal do Recôncavo da Bahia - UFRB, Brasil. Programa de Pós-Graduação em Educação do Campo - Mestrado Profissional em Educação do Campo UFRB. Grupo de Pesquisa Educação do Campo e Contemporaneidade/ Grupo de Pesquisa e Extensão em Agroecologia e Educação das Relações Étnico-Raciais. Correio eletrônico: priscilabrasileiro@ufrb.edu.br. 